International JOURNAl OF Multidisciplinary Research AND ANALysis

ISSN(print): 2643-9840, ISSN(online): 2643-9875

Volume 04 Issue 05 May 2021

DOI: 10.47191/ijmra/v4-i5-04, Impact Factor: 6.072

Page No.- $520-529$

\title{
Quality of Malaria and HIV Rapid Diagnostic Test kits (RDTs) in health facilities and medicines outlets in the Greater Accra Region of Ghana
}

\author{
Amartey $\mathrm{AO}^{1,2^{*}}$, Buabeng $\mathrm{KO}^{2}$, Mohammed $\mathrm{A}^{3}$, Maru $\mathrm{SM}^{4}$ Peeling $\mathrm{R}^{5}$, Tengey $\mathrm{S}^{6}$ \\ ${ }^{1}$ Technical Operations Division, Food and Drugs Authority, Accra, Ghana \\ ${ }^{2}$ Department of Pharmacy Practice, Faculty of Pharmacy and Pharmaceutical Sciences, Kwame Nkrumah University of \\ Science and Technology, Kumasi, Ghana. \\ ${ }^{3}$ Department of Epidemiology and Biostatistics, Kwame Nkrumah University of Science and Technology, Kumasi, Ghana. \\ ${ }^{4}$ Department of Pharmacy Practice and Pharmaceutics, School of Pharmacy, University of Nairobi, Kenya. \\ ${ }^{5}$ London School of Hygiene and Tropical Medicine, UK \\ ${ }^{6}$ Medical Waste Department, Zoompak Ghana Limited, Accra-Ghana
}

\section{ABSTRACT:}

Background: Questions remain on the quality of malaria and HIV Rapid Diagnostic Test kits (RDTs) stocked and used in health facilities in Ghana. The Food and Drugs Authority (FDA) in Ghana is mandated to regulate RDTs for quality. By this, all RDTs must be registered, and each brand given a unique registration number. This study aimed to assess the quality of malaria and HIV RDTs in health facilities in the Greater Accra Region of Ghana, using FDA standards.

Method: Data was obtained using structured questionnaire from 400 facilities in three districts in the Greater Accra region. A multi-stage sampling procedure was used to select the health facilities including retail medicine outlets. Information on the registration status of the RDTs and conditions under which they were stored were gathered. RDTs kept in air conditioned or wellventilated rooms were considered as being stored under good condition. RDTs, registered by the FDA and appropriately stored were considered to be of good quality. Data was coded, stored, and analyzed using STATA version 15.

Results: About $17 \%$ of the malaria RDTs stocked in the pharmacies were unregistered, $85.7 \%$ in hospitals were registered. Also, 83.3\% of HIV RDTs in the Policlinics were registered. Registration status of the RDTs were associated with the districts in which the health facilities were located $(p=0.006)$. The RDTs were generally stored under good conditions (99.5\%). Over forty percent (41.9\%) of user practitioners interviewed rated the quality of the malaria RDTs as good and 59.2\% rated HIV RDTs as very good.

Conclusion: Though there were some unregistered RDTs whose quality cannot be ascertained, the quality of malaria and HIV RDTs in the facilities assessed were rated as good and likely to produce good results for malaria and HIV case detection.

KEYWORDS: Quality, Malaria, HIV, Rapid Diagnostic Tests (RDTs), Ghana.

\section{INTRODUCTION}

Rapid diagnostic tests play an important role in health care delivery systems. According to the World Health Organization (WHO), Patient management depends upon the availability of reliable and accurate in-vitro diagnostics (IVDs) for clinical decisions on diagnosis and treatment. ${ }^{6,11}$ Incorrect test results may have serious health consequences. The introduction of the World Health Organization (WHO) policy on malaria case management in 2010 (Test, Track, Treat) ${ }^{11}$ resulted in an increase in Rapid Diagnostic Test (RDT) usage in malaria endemic countries. ${ }^{13}$ In Ghana, Malaria is the leading cause of morbidity and in-hospital mortality, with over 3 million cases each year. ${ }^{4}$ Over $40 \%$ of all hospital Outpatient Department (OPD) visits and $30 \%$ of hospital admissions are attributed to this disease.$^{4}$ Ghana adopted the WHO recommended "Test, Track, Treat" approach for managing malaria in 2010. It is therefore very necessary that, the quality of malaria RDT kits (mRDTs) in the health facilities is good, in order to ensure user confidence. In the absence of good quality mRDT kits, Health Care Professionals as well as patients will revert to presumptive 


\section{Quality of Malaria and HIV Rapid Diagnostic Test kits (RDTs) in health facilities and medicines outlets in the Greater Accra Region of Ghana}

diagnosis of malaria, a situation that will defeat the whole purpose of the WHO recommended "Test, Track, Treat" approach for managing malaria with all its health and economic benefits.

Even though the Ghana AIDS Commission pegs the HIV/AIDS prevalence rate at $1.6 \%$ for the year 2018 , the disease remains a big public health threat and therefore the need for proper and accurate diagnosis.

To ensure the availability of good quality malaria and HIV RDT kits as well as other RDT kits, in resource-limited settings, the WHO in the year 2008 initiated prequalification of these devices and has a list of all prequalified RDT kits. ${ }^{12}$ The IVDs prequalification process begins with the submission of a Pre-submission Form by the manufacturer to apply for prequalification. Dossier review follows. Next is Site Inspection where the manufacturing site is inspected to assess compliance with the quality management standard ISO 13485:2003. Laboratory evaluation of the RDT is performed to assess the operational and performance characteristics of the RDT. The prequalification process is well summarized in "In vitro diagnostics and laboratory technology, Prequalification of in vitro diagnostics". ${ }^{6}$

Most of the WHO prequalified RDT kits are destined for Africa ${ }^{13}$ however, with the high temperatures and humidity in a number of the countries on the continent, maintaining their quality and ensuring the availability of quality RDT kits becomes challenging. ${ }^{7}$ In Ghana, the Food and Drugs Authority (FDA) is mandated to regulate RDT kits which are classified as Medical devices. ${ }^{10,5}$ The FDA registers all brands of RDT kits in use in Ghana. Just as with the process for WHO Prequalification, the FDAs' registration process also follows the same order with the submission of an application by an applicant; this includes the completed application form together with the product dossier, samples, application fees and a covering letter.

The FDA then performs the following:

\section{$>$ Dossier/Document evaluation}

- To evaluate documentary evidence relating to the development and manufacture of the medical device, as well as issues on the safety, quality, and performance.

$>$ Good Manufacturing Practice / Quality Management System (GMP/QMS) Audit of manufacturing facility

- Provides information on ability to consistently produce quality/safe products.

$>$ Quality Evaluation of samples

- To evaluate the representative samples on the stated specifications.

$>\quad$ Import and Export Control

- Monitors to ensure that only registered products enter the country legally.

$>$ Post Market Surveillance (PMS)

- Ensure the continuous monitoring of safety, quality and good performance of registered medical devices in Ghana.

The FDA, goes through these processes to ensure that all medical devices manufactured, imported, distributed and used in Ghana are of good quality, safe to use and perform well. A lot of studies have been performed on the use of RDT kits in Ghana but very few on the quality of these devices. However, undocumented complaints from some health care workers on alleged bad quality RDT kits has driven scientific research in this direction. This study was conducted to examine the quality of Malaria and HIV RDT kits in health facilities including retail medicine outlets in the Greater Accra Region of Ghana; to confirm or otherwise the availability of any unregistered RDT kits for Malaria and HIV in health facilities including retail medicine outlets and to assess the storage conditions under which these devices are being kept since poor storage negatively affects the quality of these devices. The outcome of this study will contribute to the body of knowledge in this field and will also be expected to be fed into policy formulation in RDT kits regulation in Ghana, with the hope of ensuring that, only good quality RDTs are available for use in Ghana to protect public health and safety.

\section{MATERIALS AND METHODS}

\section{Study area}

The Greater Accra Region of Ghana is home to the capital city, which also happens to be the largest city in Ghana. According to the Ghana statistical services 2010 census projection, the total population of the region stands at 4,738,205 with Accra and Tema Metropolitan Areas being the most densely populated at 1,989,131 and 340,002 respectively. The region is made up of 16 administrative districts/metros and has a mix settlement of urban, peri-urban and rural. There are six hundred and ninety-four (694) health facilities in the region made up of the Community-Based Health Planning and Services (CHPS) facilities, clinics, District Health centers, Hospitals including teaching hospitals, maternity homes, polyclinics and psychiatric hospitals. ${ }^{3}$ Also, in respect to retail medicine outlets, there are a total of 1714 pharmacies and 1736 over the counter medicine seller's shops as of $2018 .{ }^{9}$ Some common diseases in the study area include malaria, respiratory infections, hypertension, diarrhea, diabetes, and tuberculosis. 


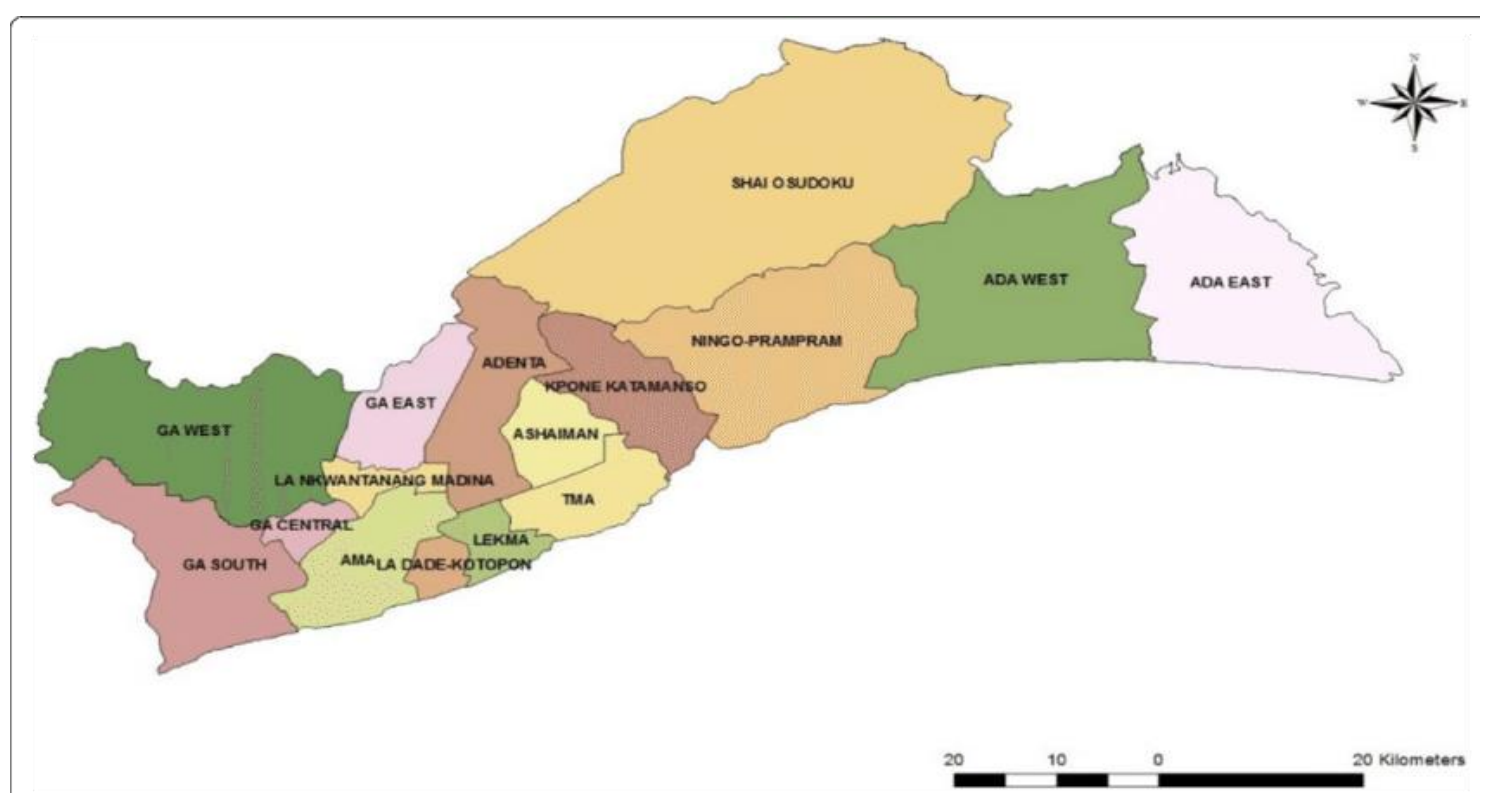

\section{Selection of facilities}

Figure 1: Map of the Greater Accra Region (Source: Ohene-Adjei et al., 2017)

The Greater Accra regional database of health facilities served as the sampling frame as compiled in the published facts and figures report 2017 of the Ghana Health Service ${ }^{3}$ and the Pharmacy Council gazette of Pharmaceutical Facilities $2018 .{ }^{9}$ The minimum sample size of 352 was determined using the classic sample size formula, with $10 \%$ response accounted for. This increases the sample size to 387 , approximated to 400 . A four-stage sampling procedure was employed; purposive sampling technique was used to select the districts to ensure a representation of urban, peri-urban and rural settlements; the second stage was a systematic selection of communities in the selected districts to ensure full coverage of each selected district, third stage was a purposive selection of health facilities to comprise a fair representation of health facilities designated as Community-Based Health Planning and Services (CHPS) facilities, health centres, Polyclinics, clinics, hospitals, pharmacies and over the counter medicine seller's shops from the selected communities. The final stage was the simple random selection of health facilities. A total of 400 facilities from three districts/metros namely Tema Metro, which can be classified as having urban and peri-urban settlements; Accra Metro, which has urban settlement and the Ga West district which has peri-urban and rural settlements participated. About $63 \%$ of the participants $(n=253)$ worked in pharmacies. Ninety two percent of the facilities $(n=368)$ were owned by private individuals (Table 1). Facility personnel with at least 3 months' work experience were recruited and interviewed in each facility using a structured questionnaire.

- $\quad$ Study Period: Data was collected in June 2019.

- Inclusion Criteria: All health facilities including medicines outlets were eligible to be part of the study after informed consent and accent have been duly and properly attained.

- Exclusion Criteria: Specialized health facilities such as eye clinics, dental clinics, mental hospitals were excluded.

- Ethical Approval: The study adhered to protecting the rights and safety of human subjects in research. As such, the study procedures and tools were submitted and subjected to ethical review by the Ghana Health Service Ethical Review Committee before commencement of the study (GHS-ERC011/01/19).

\section{- Data collection procedure}

Person-to-person interviews with facility personnel were conducted using a structured questionnaire with both closed and open-ended questions.

The interviews were done by trained data collectors who received a 3-day training on questionnaire administration and other relevant research training. Eight (8) data collectors and one supervisor were involved in the field data collection.

\section{Method}

The methodological approaches used included the collection of field level data with structured questionnaires. A review of related literature was also performed. Data collection was done electronically using the open data kit (ODK) software in order to improve the quality of data collected. An observation sheet and a checklist were used to record samples of all brands of Malaria and HIV 
Quality of Malaria and HIV Rapid Diagnostic Test kits (RDTs) in health facilities and medicines outlets in the Greater Accra Region of Ghana

RDT kits found in each facility. Visual examination of the RDT kits was performed and information on their labels critically checked and finally pictures taken for references. Also, information on the registration status of the RDT kits, which is an indicator of the RDT kit meeting all the requirements of the standard specifications and therefore registered by the FDA was collected using a current list of all registered malaria and HIV RDT kits generated by the FDA. Furthermore, information on the storage conditions such as ventilation, temperature, humidity and availability of fans, air conditioners, thermometers were also gathered. Good ventilation was captured as 'yes' and poor as 'no'. this was done by inspecting the storage area for the RDT kits after permission and using subjective assessment.

\section{Data processing and analysis}

Data obtained from the facilities was coded and compiled in the computer. Descriptive statistics was used to assess the proportions for categorical variables. Fisher's exact tests was used to examine the association between the dependent and independent variables. All statistical analyses conducted were set a $5 \%$ type I error rate. All statistical tests were conducted with a 5\% two-sided significance level using STATA version 15.

\section{RESULTS}

A total of 400 health facilities were surveyed. Majority (63.3\%) were pharmacies, with over ninety percent ( $n=368$ ) privately owned. Seventy percent of the facilities $(n=280)$ used only mRDTs, $29 \%(n=116)$ used both malaria and HIV RDTs and only $1 \%$ $(n=4)$ reported using HIV RDTs only. [Table 1 ]

\section{TABLE}

\section{CHARACTERISTICS OF FACILITIES}

\begin{tabular}{|c|c|c|}
\hline & $\begin{array}{l}\text { Frequency } \\
(n=400)\end{array}$ & $\begin{array}{r}\text { Percentage } \\
(\%)\end{array}$ \\
\hline \multicolumn{3}{|l|}{ Type of health facility Pharmacy } \\
\hline & 253 & 63.3 \\
\hline Clinic & 65 & 16.2 \\
\hline Hospital & 36 & 9.0 \\
\hline $\begin{array}{r}\text { Over the counter medicine } \\
\text { sellers' shop }\end{array}$ & 20 & 5.0 \\
\hline Health Centre & 13 & 3.3 \\
\hline Polyclinic & 6 & 1.5 \\
\hline CHPS & 5 & 1.2 \\
\hline District hospital & 2 & 0.5 \\
\hline \multicolumn{3}{|l|}{ Ownership status } \\
\hline Private & 368 & 92.0 \\
\hline Government & 28 & 7.0 \\
\hline Quasi-government & 2 & 0.5 \\
\hline Faith Based Health Institution & 2 & 0.5 \\
\hline \multicolumn{3}{|l|}{$\begin{array}{r}\text { Facility locality } \\
\end{array}$} \\
\hline Accra Metropolitan Area & 275 & 68.8 \\
\hline Tema Metropolitan Area & 90 & 22.5 \\
\hline Ga West & 35 & 8.7 \\
\hline \multicolumn{3}{|l|}{ Type of RDT used } \\
\hline mRDT only & 280 & 70 \\
\hline $\begin{array}{r}\text { HIV RDT only } \\
\end{array}$ & 4 & 1 \\
\hline Both malaria and HIV RDT & 116 & 29 \\
\hline
\end{tabular}

\section{Registration status and factors associated with the registration status of Malaria RDT kits}

Over eighty two percent (82.9\%) of the mRDT kits in the pharmacies were registered while $17.1 \%$ ( $n=43$ ) of them were unregistered. More than eighty percent (81.9\%) of the mRDT kits in the private-owned health facilities were registered with $18.1 \%$ $(n=66)$ being unregistered. Over seventy percent $(74.4 \%)$ of the mRDT kits in the health facilities located in Tema Metro were registered and $25.6 \%(n=23)$ were unregistered. All the mRDTs found in all CHPS facilities were registered. Registration status of malaria RDT kits was found to be associated with the district in which the health facilities are located $(p=0.006)$. However, type of health facility $(p=0.772)$ and ownership status $(p=0.177)$ were not significantly associated with registration status. (Table 2$)$ 
Quality of Malaria and HIV Rapid Diagnostic Test kits (RDTs) in health facilities and medicines outlets in the Greater Accra Region of Ghana

II. TABLE

REGISTRATION STATUS OF MALARIA RDT KITS

\begin{tabular}{|c|c|c|c|c|}
\hline \multirow[t]{2}{*}{ Variable } & \multicolumn{3}{|c|}{ Registration status } & \multirow[t]{2}{*}{ Fisher's exact ( $p$-value) } \\
\hline & $\begin{array}{l}\text { Registered } \\
n=329(\%)\end{array}$ & $\begin{array}{l}\text { Not registered } \\
\qquad n=67(\%)\end{array}$ & $\begin{array}{c}\text { Total } \\
\mathrm{N}=396(\%)\end{array}$ & \\
\hline Type of health facility & & & & 0.772 \\
\hline CHPS & $5(100.0)$ & $0(0.0)$ & $5(100.0)$ & \\
\hline Health Centre & $9(81.8)$ & $2(18.2)$ & $11(100.0)$ & \\
\hline Clinic & $54(83.1)$ & $11(16.9)$ & $65(100.0)$ & \\
\hline Polyclinic & $6(100.0)$ & $0(0.0)$ & $6(100.0)$ & \\
\hline Hospital & $30(85.7)$ & $5(14.3)$ & $35(100.0)$ & \\
\hline District hospital & $2(100.0)$ & $0(0.0)$ & $2(100.0)$ & \\
\hline Pharmacy/Chemist & 209 (82.9) & $43(17.1)$ & $252(100.0)$ & \\
\hline $\begin{array}{r}\text { Over the counter medicine } \\
\text { sellers' shop }\end{array}$ & $14(70.0)$ & $6(30.0)$ & $20(100.0)$ & \\
\hline Ownership status & & & & 0.177 \\
\hline Private & 298 (81.9) & $66(18.1)$ & $364(100.0)$ & \\
\hline Government & $27(96.4)$ & $1(3.6)$ & $28(100.0)$ & \\
\hline Quasi-government & $2(100.0)$ & $0(0.0)$ & $2(100.0)$ & \\
\hline Faith Based Health Institution & $2(100.0)$ & $0(0.0)$ & $2(100.0)$ & \\
\hline Facility locality & & & & 0.006 \\
\hline Accra Metro & $228(84.1)$ & 43 (15.9) & $271(100.0)$ & \\
\hline Tema Metro & 67 (74.4) & $23(25.6)$ & $90(100.0)$ & \\
\hline Ga West & 34 (97.1) & $1(2.9)$ & 35 (100.0) & \\
\hline
\end{tabular}

Registration status and factors associated with the registration status of HIV RDT kits

In the hospitals, $68.6 \%$ of HIV RDT kits were registered and $31.4 \%(n=11)$ were unregistered. The private owned heath facilities had $70.0 \%$ of the HIV RDT kits registered and $30.0 \%(n=27)$ of them unregistered. In the Accra Metropolitan Area, $75.6 \%$ of the HIV RDT kits were registered while $24.4 \%(n=22)$ were unregistered. All the HIV RDTs found in all CHPS facilities were registered. Type of health facility and ownership status were not associated with registration status of HIV RDT kits. However, the district in which the health facilities are located was significantly associated with registration status of the HIV RDT kits. (Table 3 )

III. TABLE

REGISTRATION STATUS OF HIV RDT KITS

\begin{tabular}{|c|c|c|c|c|}
\hline \multirow[t]{2}{*}{ Variable } & \multicolumn{3}{|c|}{ Registration status } & \multirow[t]{2}{*}{ Fisher's exact ( $p$-value) } \\
\hline & $\begin{array}{l}\text { Registered } \\
n=90(\%)\end{array}$ & $\begin{array}{l}\text { Not registered } \\
\qquad n=30(\%)\end{array}$ & $\begin{array}{c}\text { Total } \\
\mathrm{N}=120(\%)\end{array}$ & \\
\hline Type of health facility & & & & 0.581 \\
\hline CHPS & $3(100.0)$ & $0(0.0)$ & $3(100.0)$ & \\
\hline Health Centre & $10(76.9)$ & $3(23.1)$ & $13(100.0)$ & \\
\hline Clinic & 45 (78.9) & $12(21.1)$ & $57(100.0)$ & \\
\hline Polyclinic & $5(83.3)$ & 1 (16.7) & $6(100.0)$ & \\
\hline Hospital & $24(68.6)$ & $11(31.4)$ & $35(100.0)$ & \\
\hline District hospital & $1(50.0)$ & $1(50.0)$ & $2(100.0)$ & \\
\hline Pharmacy/Chemist & $2(50.0)$ & $2(50.0)$ & $4(100.0)$ & \\
\hline Ownership status & & & & 0.211 \\
\hline Private & $63(70.0)$ & $27(30.0)$ & $90(100.0)$ & \\
\hline Government & $23(88.5)$ & $3(11.5)$ & $26(100.0)$ & \\
\hline
\end{tabular}


Quality of Malaria and HIV Rapid Diagnostic Test kits (RDTs) in health facilities and medicines outlets in the Greater Accra Region of Ghana

\begin{tabular}{|c|c|c|c|c|}
\hline Quasi-government & $2(100.0)$ & $0(0.0)$ & $2(100.0)$ & \\
\hline Faith Based Health Institution & $2(100.0)$ & $0(0.0)$ & $2(100.0)$ & \\
\hline $\begin{array}{r}\text { District }\end{array}$ & & & & 0.0001 \\
\hline Accra Metropolitan Area & $68(75.6)$ & $22(24.4)$ & $90(100.0)$ & \\
\hline Tema Metropolitan Area & $4(33.3)$ & $8(66.7)$ & $12(100.0)$ & \\
\hline Ga West & $18(100.0)$ & $0(0.0)$ & $18(100.0)$ & \\
\hline
\end{tabular}

\section{Storage conditions}

The RDT kits were kept in good storage conditions in all the health facilities and in almost all the medicines outlets. Only two over the counter medicines sellers' shops were graded as having poor storage condition. Air conditioned or well-ventilated rooms were considered as being good conditions (Table 4).

IV. TABLE

STORAGE CONDITIONS OF RDTS

\begin{tabular}{|c|c|c|c|}
\hline \multirow[t]{3}{*}{ Variable } & \multicolumn{3}{|c|}{ Storage condition } \\
\hline & Good & Poor & Total \\
\hline & $n=398(\%)$ & $n=2(\%)$ & $\mathrm{N}=400(\%)$ \\
\hline \multicolumn{4}{|l|}{ Type of health facility } \\
\hline CHPS & $5(100.0)$ & $0(0.0)$ & $5(1.25)$ \\
\hline Health Centre & $13(100.0)$ & $0(0.0)$ & $13(3.25)$ \\
\hline Clinic & $65(100.0)$ & $0(0.0)$ & $65(16.25)$ \\
\hline Polyclinic & $6(100.0)$ & $0(0.0)$ & $6(1.50)$ \\
\hline Hospital & $36(100.0)$ & $0(0.0)$ & $36(9.00)$ \\
\hline District hospital & $2(100.0)$ & $0(0.0)$ & $2(0.50)$ \\
\hline Pharmacy/Chemist & $253(100.0)$ & $0(0.0)$ & $253(63.25)$ \\
\hline $\begin{array}{r}\text { Over the counter medicine } \\
\text { sellers' shop } \\
\text { Ownership status }\end{array}$ & $18(90.0)$ & $2(10.0)$ & $20(5.00)$ \\
\hline Private & 366 (99.5) & $2(0.5)$ & $368(92.00)$ \\
\hline Government & $28(100.0)$ & $0(0.0)$ & $28(7.00)$ \\
\hline Quasi-government & $2(100.0)$ & $0(0.0)$ & $2(0.50)$ \\
\hline Faith Based Health Institution & $2(100.0)$ & $0(0.0)$ & $2(0.50)$ \\
\hline \multicolumn{4}{|l|}{$\begin{array}{l}\text { District } \\
\end{array}$} \\
\hline Accra Metro & $274(99.6)$ & $1(0.4)$ & $275(68.75)$ \\
\hline Tema Metro & 89 (98.9) & $1(1.1)$ & $90(22.50)$ \\
\hline Ga West & 35 (100.0) & $0(0.0)$ & 35 (8.75) \\
\hline
\end{tabular}

\section{Humidity}

All the facilities (100.0\%) were graded to have a good humidity in the storage area by the research assistants. This is however speculative on the part of the research assistants because all the facilities did not have hygrometer to accurately assess the concentration of water vapour present in the air where the RDTs are stored.

\section{Availability of air condition}

All of the CHPS facilities ( $n=5,100.0 \%$ ) had no air conditions. Approximately, three-quarters $(81.2 \%)$ of the private owned facilities had air conditions in the facilities. More than half $(54.3 \%, n=19)$ of the facilities in the Ga West district did not have air conditions. The type of facility $(p=0.0001)$, ownership status $(p=0.004)$ and the districts $(p=0.0001)$ in which the facilities were located, were found to be associated with the availability of air conditions. 
Quality of Malaria and HIV Rapid Diagnostic Test kits (RDTs) in health facilities and medicines outlets in the Greater Accra Region of Ghana

PERCENTAGE DISTRIBUTION OF AVAILABILITY OF AIR CONDITIONS IN THE STORAGE AREAS OF THE FACILITIES

\begin{tabular}{|c|c|c|c|c|c|}
\hline \multirow[t]{4}{*}{ Variable } & \multicolumn{4}{|c|}{ Availability status } & \multirow{4}{*}{$\begin{array}{r}\text { Fisher's exact }^{a} p- \\
\text { value }\end{array}$} \\
\hline & Available & & & Total & \\
\hline & & available & functional & & \\
\hline & $n=316(\%)$ & $n=76(\%)$ & $n=8(\%)$ & $\mathrm{N}=400(\%)$ & \\
\hline Type of health facility & & & & & 0.0001 \\
\hline CHPS & $0(0.0)$ & $5(100.0)$ & $0(0.0)$ & $5(100.0)$ & \\
\hline Health Centre & $6(46.2)$ & $7(53.8)$ & $0(0.0)$ & $13(100.0)$ & \\
\hline Clinic & $44(67.7)$ & $21(32.3)$ & $0(0.0)$ & $65(100.0)$ & \\
\hline Polyclinic & $5(83.3)$ & $1(16.7)$ & $0(0.0)$ & $6(100.0)$ & \\
\hline Hospital & $30(83.3)$ & $6(16.7)$ & $0(0.0)$ & $36(100.0)$ & \\
\hline District hospital & $1(50.0)$ & $1(50.0)$ & $0(0.0)$ & $2(100.0)$ & \\
\hline Pharmacy/Chemist & $221(87.4)$ & $24(9.4)$ & $8(3.2)$ & $253(100.0)$ & \\
\hline $\begin{array}{l}\text { Over the counter } \\
\text { medicine sellers' shop }\end{array}$ & $9(45.0)$ & $11(55.0)$ & $0(0.0)$ & $20(100.0)$ & \\
\hline Ownership status & & & & & 0.004 \\
\hline Private & $299(81.2)$ & $61(16.6)$ & $8(2.2)$ & $368(100.0)$ & \\
\hline Government & $15(53.6)$ & $13(46.4)$ & $0(0.0)$ & $28(100.0)$ & \\
\hline Quasi-government & $1(50.0)$ & $1(50.0)$ & $0(0.0)$ & $2(100.0)$ & \\
\hline $\begin{array}{l}\text { Faith Based Health } \\
\text { Institution }\end{array}$ & $1(50.0)$ & $1(50.0)$ & $0(0.0)$ & $2(100.0)$ & \\
\hline District & & & & & 0.0001 \\
\hline Accra Metro & $221(80.4)$ & $54(19.6)$ & $0(0.0)$ & $275(100.0)$ & \\
\hline Tema Metro & $79(87.8)$ & $3(3.3)$ & $8(8.9)$ & $90(100.0)$ & \\
\hline Ga West & $16(45.7)$ & $19(54.3)$ & $0(0.0)$ & 35 (100.0) & \\
\hline
\end{tabular}

Source and Perception of Quality of RDTs

About fifty eight percent of the facilities $(n=230)$ procured their mRDTs from a local pharmaceutical vendor and $15.6 \%$ from Ghana Health service. Also, half of them (54.8\%) used one brand of mRDT and $41.7 \%$ of the study participants rated the mRDTs as good. With the HIV RDTs they were mostly supplied by the Ghana Health Service (43.8\%). Approximately ninety percent (90.1\%) of the participants disagreed that the quality of the HIV RDT is bad. HIV RDTs were mostly rated (59.2\%) as very good. (Table 6 )

SOURCE AND PERCEPTION OF QUALITY OF MALARIA AND HIV RDT

\begin{tabular}{rrr}
\hline Variable & $\begin{array}{r}\text { Frequency } \\
\text { (n) }\end{array}$ & $\begin{array}{r}\text { Percentage } \\
\text { (\%) }\end{array}$ \\
\hline $\begin{array}{r}\text { Procurement of mRDTs } \\
\text { Imported } \\
\text { Other }\end{array}$ & 62 & 15.6 \\
Supplied by Ghana Health Service & 230 & 58.1 \\
Local Pharmaceutical Vendor & 5 & 1.3 \\
\hline Procurement of HRDTs & 99 & 25.0 \\
\hline Supplied by Ghana Health Service & 53 & 44.2 \\
Local Pharmaceutical Vendor & 44 & 36.6 \\
Imported & 1.7 \\
Other & 2 & 17.5 \\
\hline Quality of HRDTs is bad & 21 & 1.7 \\
Yes & & 91.7 \\
\hline No & 2 & 110 \\
\hline
\end{tabular}


Quality of Malaria and HIV Rapid Diagnostic Test kits (RDTs) in health facilities and medicines outlets in the Greater Accra Region of Ghana

\begin{tabular}{rrr} 
Some of them & 7 & 5.8 \\
Don't know & 1 & 0.8 \\
\hline Use one brand of Malaria RDT & & 54.8 \\
Yes & 217 & 45.2 \\
\hline No & 179 & 0.8 \\
Quality of HIV RDT (rating) & 1 & 3.3 \\
Poor & 1 & 25.0 \\
Average & 4 & 59.2 \\
Good & 30 & 11.7 \\
\hline Excellent & 71 & \\
\hline Quality of Malaria RDT (rating) & 14 & 4.8 \\
Poor & & 12.4 \\
Average & 19 & 41.9 \\
Good & 49 & 37.4 \\
Very good & 166 & 3.5 \\
Excellent & 148 & 14 \\
\hline
\end{tabular}

\section{DISCUSSIONS}

A registered RDT kit gives an assurance of a good quality device due to the stringent regulatory process the RDT kit is subjected to at the FDA. Two major parameters amongst others that the RDT should pass at the FDA are sensitivity which should be $95 \%$ or higher, and specificity also $95 \%$ or higher. Findings of the study suggests that majority of both malaria and HIV RDT kits in health facilities as well as in retail medicines outlets were registered. This implies they had sensitivities and specificities $95 \%$ or higher and therefore suitable for use as per the FDA standards. There are several other studies, where sensitivities as high as 100\% Baiden et al., (2012), 100\% Evelyn et al., (2015), and specificities as high as 100\% (Nicastri et al., 2009), 98\% Evelyn et al., (2015) were noted in the formal health care sectors and retail sectors respectively. Also, current study revealed that majority of the RDTs are registered. This is to be expected as the FDA, the regulator of these devices has systems in place to ensure that the RDTs are registered before they can be imported, distributed, sold, and used in the country. Almost all these RDT kits are imported devices as a result, even those that are registered with the FDA do not have their FDA registration numbers printed or embossed of their outer packaging material or label, this therefore may affect participants' capability to promptly detect an unregistered RDT kit. However, with the locally produced RDT kits, it is mandatory to have the FDA registration number displayed on the outer packaging material or label of the device making it easier to verify the registration status of locally made devices. There could be other reasons also for the presence of unregistered RDT kits in these facilities as confirmed by the study but that needs to be investigated. The presence of these unregistered malaria and HIV RDT kits is quite alarming as their quality cannot be guaranteed, a situation that could compromise the quality of health care delivery in terms of diagnosis and treatment as in the case of a false positive result, wrong treatment will be given and in the case of a false negative result, the denial of the much-needed medication.

Registration status of both malaria and HIV RDT kits were found to be associated with the district in which the health facilities are located. Tema Metro which has a mix of urban and peri urban settlements had the highest percentages of unregistered RDT kits both malaria and HIV, whilst Ga West which consist of peri urban and rural settlements had the lowest percentages of unregistered malaria and HIV RDT kits. However, type of health facility and ownership status were not significantly associated with registration status. This is the first study of this kind so there are no existing studies to compare results with, as to why Ga West District has the lowest percentage of unregistered mRDT kits and zero percent of unregistered HIV RDT kits and Tema Metro having the highest percentages of unregistered malaria and HIV RDT kits remains to be investigated.

\section{Storage Conditions}

Ghana is a hot and humid country. Unfortunately, RDTs are negatively affected by high temperatures and humidity. The results of the study indicate that the RDT kits were kept in good storage conditions in all the health facilities. The type of the health facility, ownership status, and the district in which the health facilities were located had no statistically significant influence on the storage conditions of the RDT kits.

None of the facilities visited had a hygrometer to accurately assess the concentration of water vapour present in the air where the RDT kits are stored even though they were all graded to have good humidity in the storage area. This was however speculative on the part of the research assistants. 


\section{Quality of Malaria and HIV Rapid Diagnostic Test kits (RDTs) in health facilities and medicines outlets in the Greater Accra Region of Ghana}

Approximately, three-quarters of the private owned facilities had air conditions in the facilities. More than half $(57.6 \%, \mathrm{n}=19)$ of the facilities in the Ga West district did not have air conditions and all the CHPS facilities did not have air conditions. This is to be expected since these CHPS facilities are usually located in peri urban and rural communities, maintain and running air conditioners could be challenging as CHIPS facilities are government owned and they usually operate on tight budgets. The ownership status $(p=0.004)$ and the districts $(p=0.0001)$ in which the facilities are located were found to be associated with the availability of air conditions.

A registered RDT kit that is appropriately stored will maintain its quality characteristics till its expiry date.

\section{CONCLUSIONS}

Though there were some unregistered RDT kits whose quality cannot be ascertained, the quality of Malaria and HIV RDT kits in the health facilities including those in the retail medicine outlets assessed, were rated as good and likely to produce good results for malaria and HIV case detection.

\section{RECOMMENDATIONS}

The need to have reliable and quality RDT kits to guide disease identification for appropriate therapy in health facilities is a must for a country like Ghana. The Food and Drugs Authority of Ghana, in implementing its mandate of regulating medical devices to ensure that only good quality RDT kits are available for use in Ghana, has in place an elaborate regulatory process. However, there still are some unregistered RDT kits in health facilities including retail medicine outlets. In order to curtail such occurrences, the following recommendations should be considered:

1. A study to identify the sources of such unregistered RDT kits for the implementation of appropriate regulatory measures.

2. A further study perhaps qualitative to understand the motivation underlining the purchase of unregistered RDTs by Personnel of Health Facilities both for use and for sale. This will enable a more tailored approach to correction.

\section{LIMITATION}

Some noteworthy limitations were identified in this study. Firstly, none of the facilities visited had a hygrometer to accurately assess the concentration of water vapour present in the air where the RDT kits are stored even though they were all graded to have good humidity in the storage area. Also, no facility had a thermometer to read the temperature in the storage room.

\section{ACKNOWLEDGMENT}

I am most grateful to the data collectors who collected quality data to enable me come up with publication and then to Richard Kwasi Opong of the Food and Drugs Authority Ghana for all the I.T support.

\section{REFERENCES}

1) Baiden F., Webster J., Tivura M., et al. (2012). Accuracy of rapid tests for malaria and treatment outcomes for malaria and non-malaria cases among under-five children in rural Ghana. PLOS ONE; 7:e34073.

2) Evelyn KA, Solomon N, Harriet AB, Constance BP, Bonnie C, Christopher J M W (2015). The impact of providing rapid diagnostic malaria tests on fever management in the private retail sector in Ghana: a cluster randomized trial. $B M J$; 350:h1019.

3) Ghana Health Service Facts and Figures 2017 publications http://www.ghanahealthservice.org/ghs-itemetails.php? cid $=5 \&$ scid $=55 \&$ iid $=128$ (last accessed October 30, 2018)

4) Ghana Statistical Service (GSS), Ghana Health Service (GHS), and ICF International. 2015. Ghana Demographic and Health Survey 2014. Rockville, Maryland, USA: GSS, GHS, and ICF International

5) Global Harmonization Task Force: Definition of the Terms "Medical Device" and "In Vitro Diagnostic (IVD) Medical Device GHTF/SG1/N071:2012. In Book Definition of the Terms "Medical Device" and "In Vitro Diagnostic (IVD) Medical Device GHTF/SG1/N071:2012; 2012

6) In vitro diagnostics and laboratory technology> Prequalification of in vitro diagnostics https://www.who.int/diagnostics_laboratory/en/(last accessed October 30, 2018)

7) Malaria Rapid Diagnostic Test Performance - Summary results of WHO product testing of malaria RDTs: rounds 1-7 (2008-2016)www.who.int/malaria/publications/atoz/978924151268/en/(last accessed October $30,2018)$ 
Quality of Malaria and HIV Rapid Diagnostic Test kits (RDTs) in health facilities and medicines outlets in the Greater Accra Region of Ghana

8) Nicastri E., Bevilacqua N., Schepisi MS., et al. (2009). Accuracy of malaria diagnosis by microscopy, rapid diagnostic test, and PCR methods and evidence of antimalarial overprescription in non-severe febrile patients in two Tanzanian hospitals. Am. J. Trop. Med. Hyg.; 80:712-17.

9) Pharmacy Council, Ghana. Gazette of Pharmaceutical facilities, 2018.

10) Public Health Act 2012, Act 851 Republic of Ghana

11) World Health Organization. Guidelines for the treatment of malaria. 2nd ed. Geneva: ${ }^{12}$ World Health Organization; 2010

12) WHO List of prequalified in vitro diagnostic products; Last update $4^{\text {th }}$ April 2019 www.who.int/diagnostics laboratory/evaluation/190404 prequalified product list.pdf

13) World Health Organization. 2019; Rapid diagnostic tests http://www.who.int/malaria/areas/diagnosis/rapid diagnostic tests/en/ 